\title{
Neuromyelitis optica MOG-IgG causes reversible lesions in mouse brain
}

\author{
Samira Saadoun ${ }^{1}$, Patrick Waters ${ }^{2}$, Gregory P Owens ${ }^{3}$, Jeffrey L Bennett ${ }^{3,4}$, Angela Vincent ${ }^{2}$ \\ and Marios C Papadopoulos ${ }^{1 *}$
}

\begin{abstract}
Introduction: Antibodies against myelin oligodendrocyte glycoprotein (MOG-lgG) are present in some neuromyelitis optica patients who lack antibodies against aquaporin-4 (AQP4-lgG). The effects of neuromyelitis optica MOG-lgG in the central nervous system have not been investigated in vivo. We microinjected MOG-lgG, obtained from patients with neuromyelitis optica, into mouse brains and compared the results with AQP4-lgG.

Results: MOG-IgG caused myelin changes and altered the expression of axonal proteins that are essential for action potential firing, but did not produce inflammation, axonal loss, neuronal or astrocyte death. These changes were independent of complement and recovered within two weeks. By contrast, AQP4-lgG produced complement-mediated myelin loss, neuronal and astrocyte death with limited recovery at two weeks.
\end{abstract}

Conclusions: These differences mirror the better outcomes for MOG-IgG compared with AQP4-lgG patients and raise the possibility that MOG-lgG contributes to pathology in some neuromyelitis optica patients.

Keywords: Antibody, Demyelination, Myelin oligodendrocyte glycoprotein, Neuromyelitis optica

\section{Introduction}

Most neuromyelitis optica (NMO) patients have IgG against aquaporin-4 (AQP4), here termed AQP4-IgG $[1,2]$. AQP4 is a water channel protein found in astrocytes throughout the central nervous system (CNS), especially in perivascular astrocyte foot processes [3]. In cultured cells, AQP4-IgG binds extracellular conformational domains of AQP4 and activates complement, causing cell lysis [4]. In mice, intracerebral injection of AQP4-IgG activates co-injected human complement $\left(\mathrm{C}_{\mathrm{hu}}\right)$ and damages the astrocytes [5,6]. Inflammatory cells then enter the lesion causing further tissue injury including demyelination and axonal damage. In AQP4IgG NMO patients, recovery after an attack is usually limited [7-9].

A few NMO patients without AQP4-IgG have IgG against myelin oligodendrocyte glycoprotein (MOG-IgG), which recognize extracellular conformational domains of MOG [10-13]. MOG is expressed on the outer surface of CNS myelin sheaths and comprises about $0.05 \%$ of total

\footnotetext{
* Correspondence: mpapadop@sgul.ac.uk

'Academic Neurosurgery Unit, St. George's, University of London, London, UK Full list of author information is available at the end of the article
}

myelin protein [14]. There is mounting evidence that MOG-IgG NMO has more favorable clinical outcome than AQP4-IgG NMO, with resolution of imaging abnormalities $[10,11,15,16]$. It is currently unclear whether MOG-IgG plays any role in NMO by causing lesions in the CNS in vivo. Here we compared the effects of MOGIgG with those of AQP4-IgG in the intracerebral injection mouse model. We used total IgG from a normal subject $\left(\mathrm{IgG}_{\mathrm{CON}}\right)$ and from NMO patients with AQP4-IgG ( $\left.\operatorname{IgG}_{\mathrm{AQP} 4}\right)$ or MOG-IgG (IgG $\left.\mathrm{IOG}_{\mathrm{MO}}\right)$.

\section{Materials and methods}

\section{IgG and complement}

NMO patients with MOG-IgG or AQP4-IgG were identified using live cell-based assays. Briefly, AQP4-IgG and MOG-IgG positivity was determined by visualization of binding to human embryonic kidney cells, transfected with the extracellular and trans-membrane domains of MOG or with full-length M23-AQP4. Details of the assays are given elsewhere $[5,10,11,15]$. IgG was purified using Protein G from sera or plasmas of five patients with AQP4-IgG $\mathrm{NMO}$, five MOG-IgG NMO or one healthy volunteer. The effect of injecting IgG and $C_{h u}$ from healthy volunteers into mouse brain was extensively investigated in our earlier 
studies $[5,17,18]$. The purified, dialysed and pooled total IgG preparations $(6-38 \mathrm{mg} / \mathrm{ml})$ are termed $\operatorname{IgG}_{\mathrm{AQP} 4}$, $\mathrm{IgG}_{\mathrm{MOG}}$ and $\mathrm{IgG}_{\mathrm{CON}}$. Clinical details of the $5 \mathrm{AQP4}-\mathrm{IgG}+$ [5] and 5 MOG-IgG + $[11,15]$ patients are given elsewhere. To deplete MOG-IgG, the IgG $_{\text {MOG }}$ was adsorbed by incubation with MOG-HEK cells until MOG-IgG became undetectable (IgG $\mathrm{IgOG}_{\text {(AdsMOG-HEK) }}$ ). IgG $\mathrm{IgOG}_{\text {MOG }}$ adsorbed against untransfected HEK cells (IgG MOG(AdsHEK) $_{\text {) was }}$ used as control. A chimeric mouse-human recombinant monoclonal anti-mouse MOG antibody, MOG-IgG ${ }_{2 \mathrm{~B} 7}$, was produced as described [19]. Human recombinant monoclonal anti-AQP4 $\mathrm{IgG}_{1}$, termed AQP4-IgG ${ }_{53}$, was also generated [20]. A measles virus-specific antibody termed $\mathrm{CON}-\mathrm{IgG}_{2 \mathrm{~B} 4}$ was used as isotype control [20]. The source of $C_{h u}$ was fresh serum from healthy volunteers [5].

\section{Mice}

Experiments were performed at St. George's, University of London using CD1 mice $8-1230-35$ g, $8-12$ w old. Protocols were approved by the British Home Office (Project Licence, PPL 70/7081). After administering 2,2,2tribromoethanol i.p., mice were mounted onto a stereotactic frame (Benchmark, Neurolab, St Louis, MO, USA). Four burrholes were made on the right side using a high speed drill (0.7 mm burr, Foredom, Bethel, CT, USA) at the following coordinates in millimetres from the bregma (lateral, anterior): $(1,0),(1,-1),(1,-2),(2,-1)$. Mice were allocated to the different experimental groups by a person unaware of the aim of the study. A 30 g needle attached to $50 \mathrm{ml}$ gas-tight glass syringe (Hamilton, Reno, NV, USA) was inserted $3 \mathrm{~mm}$ deep to micro-infuse $(1 \mu \mathrm{L} / \mathrm{min})$ into the right hemisphere $16.8 \mu \mathrm{L} \operatorname{IgG}_{\mathrm{MOG}}$, $\operatorname{IgG}_{\mathrm{AQP} 4}$ or $\mathrm{IgG}_{\mathrm{CON}}$ or $16.8 \mu \mathrm{L}(20 \mu \mathrm{g})$ MOG-IgG ${ }_{2 \mathrm{~B} 7}$ or AQP4-IgG $53+11.2 \mu \mathrm{L}$ $\mathrm{C}_{\mathrm{hu}}$ (or normal saline) as described [5]. Rectal temperature was kept $37-38^{\circ} \mathrm{C}$ with a heating lamp. After regaining the righting reflex, mice were returned to their cages, kept in 12 hour light/dark cycle and given water and normal chow ad libitum. Mice (5 per group) were killed at 24 hours, seven days or two weeks. Investigators were unaware of which antibody was injected.

\section{Mouse brain histology and immunohistology}

Mice were anaesthetized and perfused-fixed by injecting $4 \%$ formaldehyde through the left cardiac ventricle. Brains were removed, post-fixed in $4 \%$ formaldehyde overnight and processed into paraffin. Coronal tissue sections $(7 \mu \mathrm{m}$ thick) through the injection tract were stained with $\mathrm{H}+\mathrm{E}$, Luxol Fast Blue (LFB) [5] or immunostained.

For diaminobenzidine immunostaining, the sections were unmasked in citrate, incubated with primary antibody (one hour, $25^{\circ} \mathrm{C}$ ), biotinylated secondary antibody $\left(1: 500\right.$, one hour, $\left.25^{\circ} \mathrm{C}\right)$ and visualized using the Vectastain
HRP kit (Vector Labs, Peterborough, UK). We counterstained nuclei with haematoxylin. Primary antibodies were rabbit anti-AQP4 (1:100), rabbit anti-glial fibrillary acidic protein (GFAP, 1:200), mouse anti-NeuN (1:200), (Millipore, Livingstone, UK), mouse anti-myelin basic protein (MBP, 1:400, Leica, Newcastle, UK), mouse antineurofilament-70 (1:600, DAKO, Ely, UK), rabbit antiC5b-9 (1:100, Abcam, Cambridge, UK) and rat anti-CD45 (1:200, BD Bioscience, Oxford, UK). Samples were then incubated with the appropriate species biotinylated secondary antibody (1:500, Vector Laboratories). Immunostaining was visualized brown using the Vectastain horseradish peroxidase kit (Vector Laboratories) followed by diaminobenzidine $/ \mathrm{H}_{2} \mathrm{O}_{2}$. Nuclei were counterstained blue with haematoxylin.

For immunofluorescence staining, we used rabbit antiAnkyrin G (AnkG, InsightBio, Wembley, UK) or rabbit anti-Contactin associated protein (Caspr) from Abcam $\left(1: 200,12\right.$ hours, $\left.25^{\circ} \mathrm{C}\right)$ followed by Alexafluor-linked anti-rabbit antibody $\left(1: 200\right.$, one hour, $25^{\circ} \mathrm{C}$, Invitrogen, Paisley, UK).

To determine MOG-IgG binding to mouse brain sections, brains were removed, immersed in 30\% sucrose overnight, embedded in OCT and cut into $7 \mu \mathrm{m}$ sections. These were fixed in acetone and exposed to IgG $_{\text {MOG(AdsHEK) }}, \quad \operatorname{IgG}_{\text {MOG(AdsMOG-HEK) }}, \quad \operatorname{IgG}_{\mathrm{CON}}$ (1:100) or MOG-IgG $2 \mathrm{~b} 7(1 \mathrm{mg} / \mathrm{mL}) \pm$ rabbit anti-MOG $(1: 100$, InsightBio) for one hour at $25^{\circ} \mathrm{C}$ followed by Alexafluorlinked anti-human \pm anti-rabbit IgG (1:200, one hour, $25^{\circ} \mathrm{C}$, Invitrogen) and DAPI.

Photomicrographs were taken using an Olympus BX51 microscope.

\section{Data analysis}

Coded photomicrographs were analysed with ImageJ (v1.45S, NIH). Neurofilament immunoreactivity in the injected hemisphere was quantified as mean staining intensity minus background. AnkG and Caspr expression was the number of fluorescent spots $/ \mathrm{mm}^{2}$ in four photomicrographs, $90 \mu \mathrm{m} \times 67 \mu \mathrm{m}$, taken from the injected hemisphere $0.5 \mathrm{~mm}$ from the needle tract. After subtracting background, formatting images to 8-bit, adjusting threshold, the 'analyse particles' function of Image J was used. Spots $<0.01 \mu \mathrm{m}^{2}$ were excluded as noise.

\section{Statistics}

Data are mean \pm standard error. We used Student t-test or ANOVA with Student-Newman-Keuls post-hoc analysis. Significance is $P<0.05^{*}, 0.01^{* * *}, 0.001^{* * * *}$.

\section{Results}

Lesions induced by $\lg \mathrm{G}_{\mathrm{MOG}}$ compared to $\lg \mathrm{G}_{\mathrm{AQP} 4}$ $\mathrm{IgG}_{\mathrm{MOG}}+\mathrm{C}_{\mathrm{hu}}$ caused brain edema at 24 hours, but by seven days and two weeks the brain appeared normal 
(Figure 1A). Although IgG $\operatorname{IQP} 4+\mathrm{C}_{\mathrm{hu}}$ also caused edema at 24 hours, at seven days there was marked leukocyte infiltration and by two weeks reactive gliosis (Figure 1A). IgG $G_{\text {MOG }}+\mathrm{C}_{\mathrm{hu}}$ caused loss of Luxol Fast Blue (LFB) staining at 24 hours, but this had reversed by two weeks, while the $\operatorname{IgG}_{\mathrm{AQP} 4}+\mathrm{C}_{\mathrm{hu}}$ - injected tissue showed increased loss of LFB staining at seven days and only partially recovered at two weeks (Figure 1B). The recruitment of inflammatory cells also differed markedly between the two preparations. $\mathrm{IgG}_{\mathrm{MOG}}+\mathrm{C}_{\mathrm{hu}}$ did not produce inflammation while $\operatorname{IgG}_{\mathrm{AQP} 4}+\mathrm{C}_{\mathrm{hu}}$ caused inflammation at 24 hours (perivascular neutrophils) and seven days (mostly macrophages) (Figure 1C).

We immunostained for two astrocyte markers, AQP4 and GFAP. Loss of AQP4 and GFAP was seen in
$\mathrm{IgG}_{\mathrm{AQP} 4}+\mathrm{C}_{\mathrm{hu}}$ - injected brains (at 24 hours and seven days) but $\mathrm{IgG}_{\mathrm{MOG}}+\mathrm{C}_{\mathrm{hu}}$ did not reduce AQP4 and GFAP (Figure 2). At two weeks there was marked gliosis (increased AQP4 and GFAP) in brains injected with $\mathrm{IgG}_{\mathrm{AQP} 4}+\mathrm{C}_{\mathrm{hu}}$, compared to little gliosis in brains that received $I_{\text {gOG }}+C_{\text {hu }}$ (Figure 2 ).

\section{MOG-IgG binds mouse MOG and causes loss of LFB staining}

To confirm that $\operatorname{IgG}_{\mathrm{MOG}}$ binds mouse myelin, it was applied to brain sections. $\operatorname{IgG}_{\mathrm{MOG}}$ bound the corpus callosum; binding co-localized with a commercial anti-

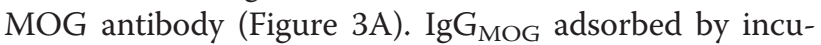
bation with MOG-expressing human embryonic kidney (MOG-HEK) cells until MOG-IgG became undetectable
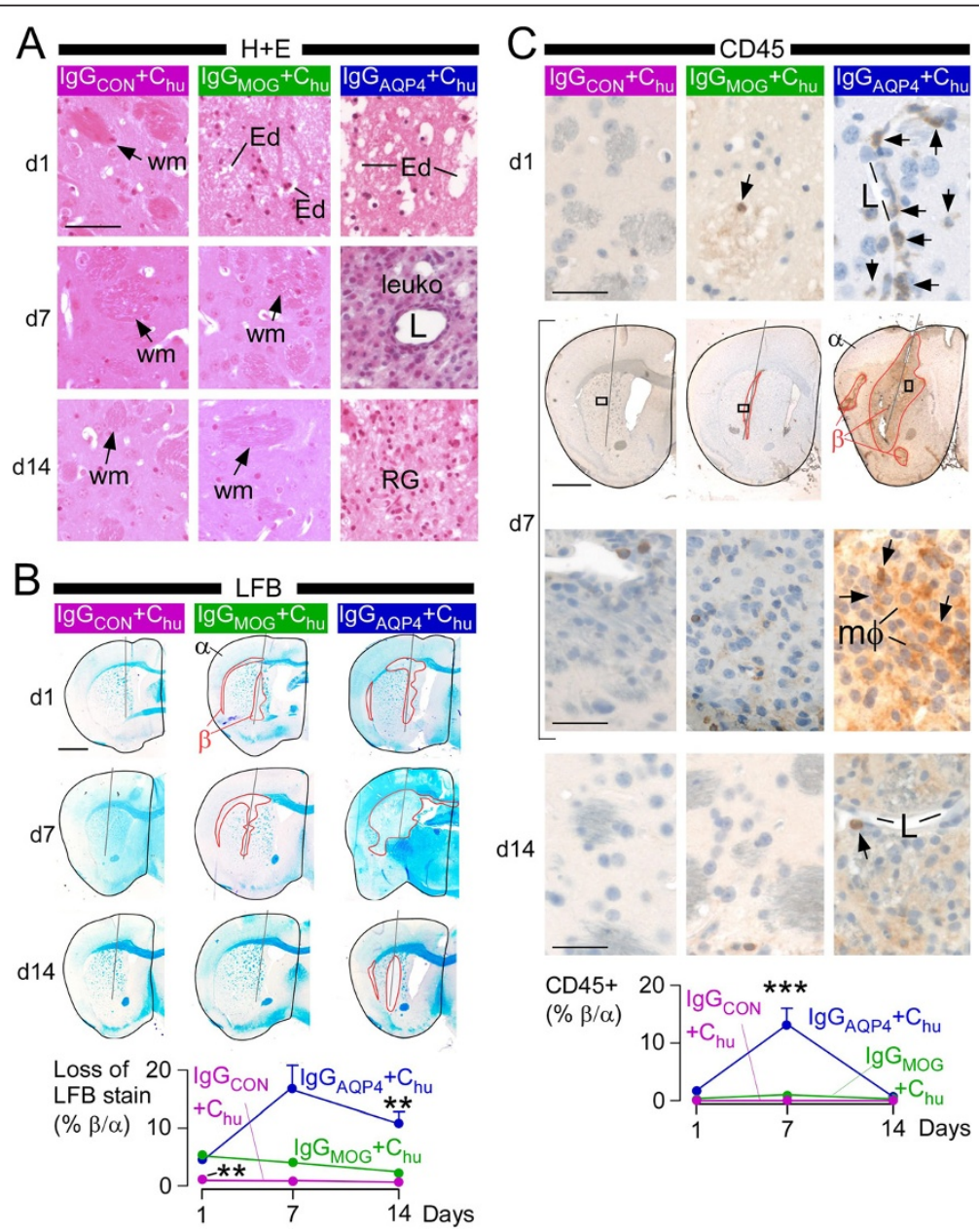

Figure 1 Brain lesions caused by MOG-IgG and AQP4-IgG. Mice received IgG $G_{C O N}+C_{h u}$ (purple), $\lg G_{M O G}+C_{h u}$ (green) or lgG $G_{A Q P 4}+C_{h u}$ (blue), were killed at 24 hours (d1), seven days (d7) or two weeks (d14) and coronal brain sections were cut through the injection site. $\mathbf{A}$. $\mathrm{H}+\mathrm{E}$ staining. Ed, edema; L, lumen; leuko, leukocytes; RG, reactive glia; wm, white matter. B. (Top) LFB staining. Red line, loss of LFB staining. (Bottom) \% Loss of LFB stain (area without LFB/ipsilateral hemispheric area) vs. days since injection. C. (Top) CD45 immunostain. Each boxed area in d7 top is shown magnified below. Arrows, CD45+ cells; L, vessel lumen; mф, macrophages. (Bottom) \% CD45+ area (CD45+ area/ipsilateral hemispheric area) vs. days since injection. Mean \pm SEM, 5 mice per group. $P<0.01^{* *}, 0.001^{* * *}$ (compared with each of the other two groups). Bar $50 \mu \mathrm{m}$ (A), $1 \mathrm{~mm}$ (B, C d7 top), $20 \mu \mathrm{m}$ (C d7 bottom). 


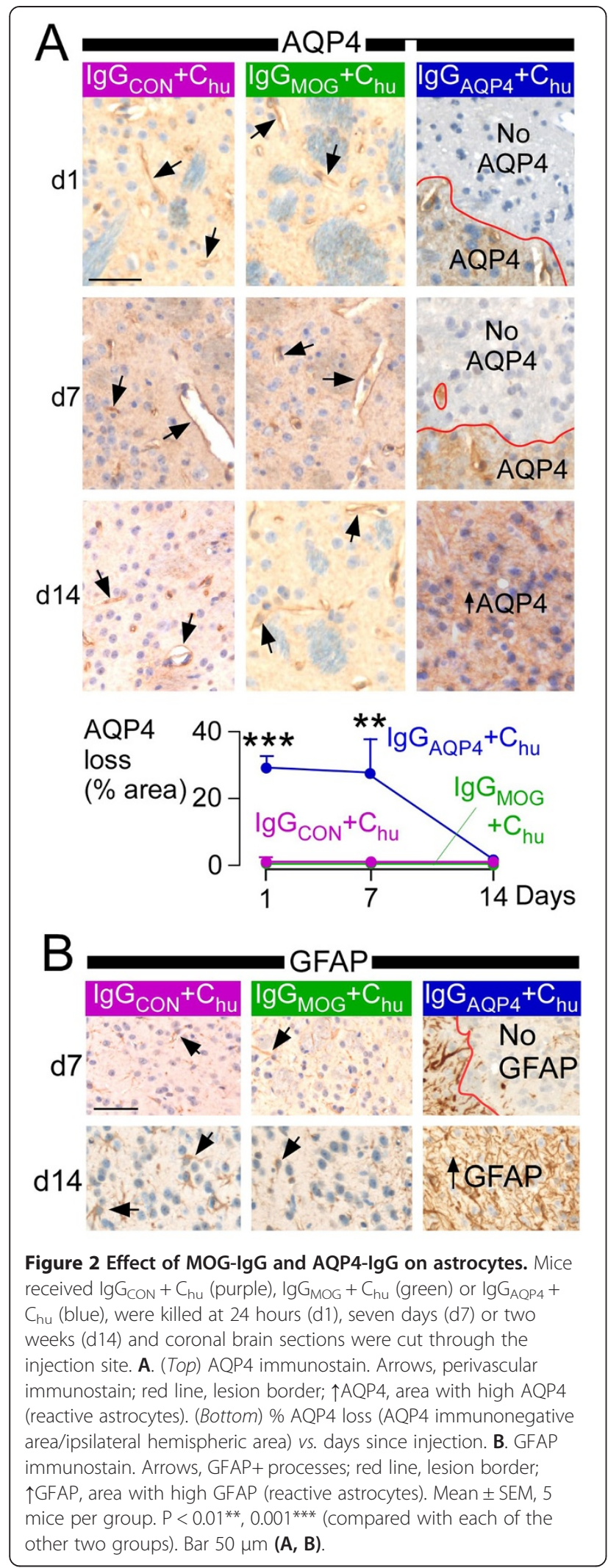

(IgG $\left.\mathrm{IMOG}_{\text {(AdsMOG-HEK) }}\right)$ did not bind the corpus callosum, unlike IgG $_{M O G}$ adsorbed against untransfected HEK cells (IgG $\mathrm{G}_{\mathrm{MOG} \text { (AdsHEK) }}$ ) (Figure $3 \mathrm{~B}$ ). To confirm that the MOG-IgG was responsible for the loss of LFB staining, the two adsorbed preparations were injected with $C_{h u}$ and mice were killed at seven days. Loss of LFB staining in the injected hemisphere was only found when $\mathrm{IgG}_{\mathrm{MOG} \text { (AdsHEK) }}+\mathrm{C}_{\mathrm{hu}}$ was used (Figure $3 \mathrm{C}$ ).

\section{MOG-IgG ${ }_{2 B 7}$ causes loss of LFB staining largely}

\section{independent of immune cells or complement activation}

In case the amount of MOG-IgG in the patient preparations was insufficient to cause inflammatory cell infiltration, a large amount $(20 \mu \mathrm{g})$ of the humanized anti-mouse MOG-IgG ${ }_{2 B 7}$ was co-injected with $C_{h u}$. At seven days, MOG-IgG $\mathrm{IB}_{2 \mathrm{~B}}+\mathrm{C}_{\mathrm{hu}}$ caused loss of LFB staining, but without inflammatory cell infiltration (Figure 4A). At 24 hours after injecting MOG-IgG $\operatorname{IgB}_{2}+\mathrm{C}_{\mathrm{hu}}$ there was faint C5b-9 immunoreactivity in white matter tracts suggesting slight complement activation, whereas injection of a monoclonal recombinant anti-AQP4 $\left(\mathrm{AQP} 4-\mathrm{IgG}_{53}\right)+\mathrm{C}_{\mathrm{hu}}$ caused strong perivascular C5b-9 immunoreactivity (Figure 4B). Moreover, intracerebral injection of MOG-IgG $\mathrm{IB}_{2}$ without $\mathrm{C}_{\mathrm{hu}}$ produced loss of LFB staining at 24 hours similar to MOG-IgG ${ }_{2 \mathrm{~B} 7}+\mathrm{C}_{\mathrm{hu}}$ (Figure $4 \mathrm{C}$ ).

\section{MOG-IgG causes reversible damage to myelinated axons}

At two weeks there was marked neuronal loss in $\mathrm{IgG}_{\mathrm{AQP} 4}+\mathrm{C}_{\mathrm{hu}}$ lesions compared to little neuronal loss in brains injected with $\operatorname{IgG}_{\mathrm{MOG}}+\mathrm{C}_{\mathrm{hu}}$ (Figure $5 \mathrm{~A}$ ). We investigated the effect of $\mathrm{IgG}_{\mathrm{MOG}}+\mathrm{C}_{\mathrm{hu}}$ on myelin and axonal proteins including myelin basic protein (MBP), neurofilament, ankyrin G (AnkG) and contactin associated protein (Caspr) (Figure 5B). MBP adheres adjacent cytoplasmic faces of myelin together, neurofilament provides structural support for axons, AnkG clusters voltage-gated $\mathrm{Na}^{+}$channels at nodes of Ranvier [21] and Caspr attaches paranodal myelin loops to the axons [22]. At 24 hours after $\operatorname{IgG}_{\mathrm{MOG}}+\mathrm{C}_{\mathrm{hu}}$ injection, MBP expression appeared abnormal (Figure $5 \mathrm{C}$ ) and there was significant reduction in AnkG (Figure 5D) and Caspr (Figure 5E) immunoreactivities. At two weeks, the MOG-IgG $+\mathrm{C}_{\mathrm{hu}}$ - induced changes in MBP, AnkG and Caspr had recovered and neurofilament expression was normal (Figure 5F), indicating intact axons.

\section{Discussion}

Although there is growing interest in the potential pathogenicity of MOG antibodies in NMO, the effects of NMO MOG-IgG have not been explored in vivo. Our results indicate that MOG-IgG directly damages myelin. The detrimental effects of MOG-IgG markedly differ from those of AQP4-IgG and are reversible (see Table 1). 


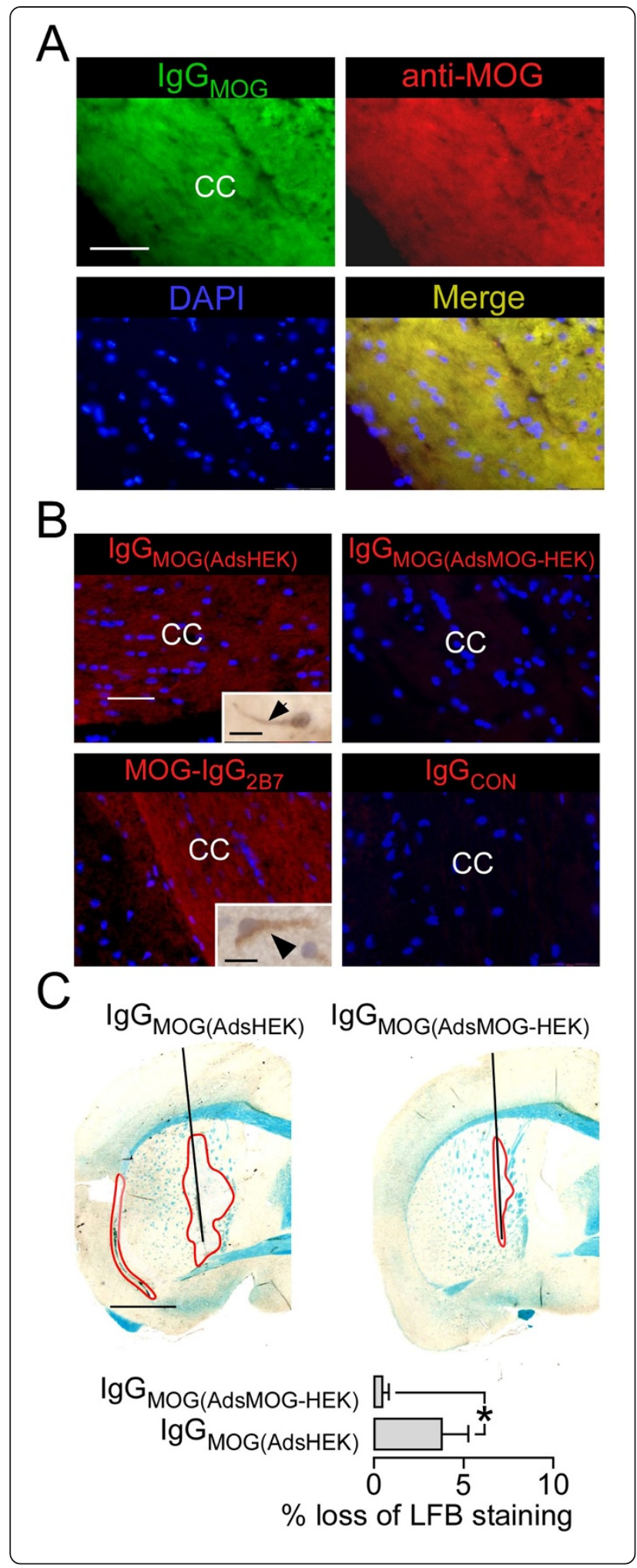

Figure 3 MOG-IgG binds mouse MOG and causes loss of LFB staining. A. Mouse corpus callosum (CC) fluorescently immunostained with IgGMOG (green) and anti-MOG (red). DAPI nuclear stain. B. CC

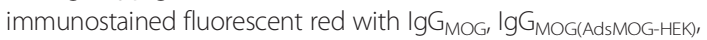
MOG-lgG $G_{2 B 7}$ and $\lg G_{C O N}$. DAPI nuclear stain. Insets - immunopositive (DAB) gray matter neurons. C. Mouse brain injected with $\lg G_{M O G(A d s H E K)}+C_{\text {hu }}$ or lgG $G_{\text {MOG(AdsMOG-HEK) }}+C_{\text {hu. }}$ (Top) LFB stained sections at 24 hours. Red line, no LFB staining. (Bottom). Data summary. 5 mice per group. Mean \pm SEM. $P<0.05^{*}$. Bar $10 \mu \mathrm{m}$ (A insets), $50 \mu \mathrm{m}$ (A, B), $1 \mathrm{~mm}$ (C).

AQP4-IgG lesions are characterized by astrocyte damage followed by leukocyte infiltration that entirely depend on complement activation [5]. We showed that recovery of myelin loss in AQP4-IgG lesions is limited, with gliosis and neuronal death. This finding may explain why clinical recovery after AQP4-IgG NMO attacks is often limited [7-9]. By contrast, MOG-IgG, as examined here, damages myelin and axons temporarily, with little complement activation, and no leukocyte infiltration. The myelin and axonal recovery and lack of neuronal death mirror the reported good outcomes of MOG-IgG NMO patients $[10,11,15,16]$.

One study suggested that IgG $_{\text {MOG }}$ obtained from children with demyelination does not bind mouse MOG [23], but another study showed that human MOG-IgG binds mouse MOG [24]. Our $\operatorname{IgG}_{\mathrm{MOG}}$ samples obtained from adult NMO patients, and the anti-mouse MOGspecific monoclonal antibody, both recognized mouse MOG in frozen brain sections, and produced comparable LFB loss without inflammation. This discrepancy may be due to differences in MOG-IgG levels and specificity or differences in MOG glycosylation state, which plays a key role in MOG-IgG binding [24], between children and adults.

The effects of MOG-IgG on cultured oligodendrocytes have already been studied. MOG-IgG binds extracellular epitopes on MOG [23] and can cause crosslinking [25] and internalization [12] of MOG molecules and reversible retraction of oligodendrocyte processes [25]. At high concentration, MOG-IgG causes complement-mediated lysis of MOG-expressing cells [12]. Passive transfer of MOGIgG antibodies exacerbates CNS damage in experimental autoimmune encephalomyelitis rodent models in which cellular immunity is the predominant pathogenic mechanism [26,27]. Using the intracerebral injection mouse model, we have shown unequivocally that NMO MOGIgG directly damages myelin in vivo independent of preexisting cellular immunity and complement.

MOG-IgG changed MBP architecture and reduced expression of axonal proteins. Caspr and AnkG are required for the integrity of the nodes of Ranvier and normal action potential firing [21,22]. Mice that lack MBP have a 


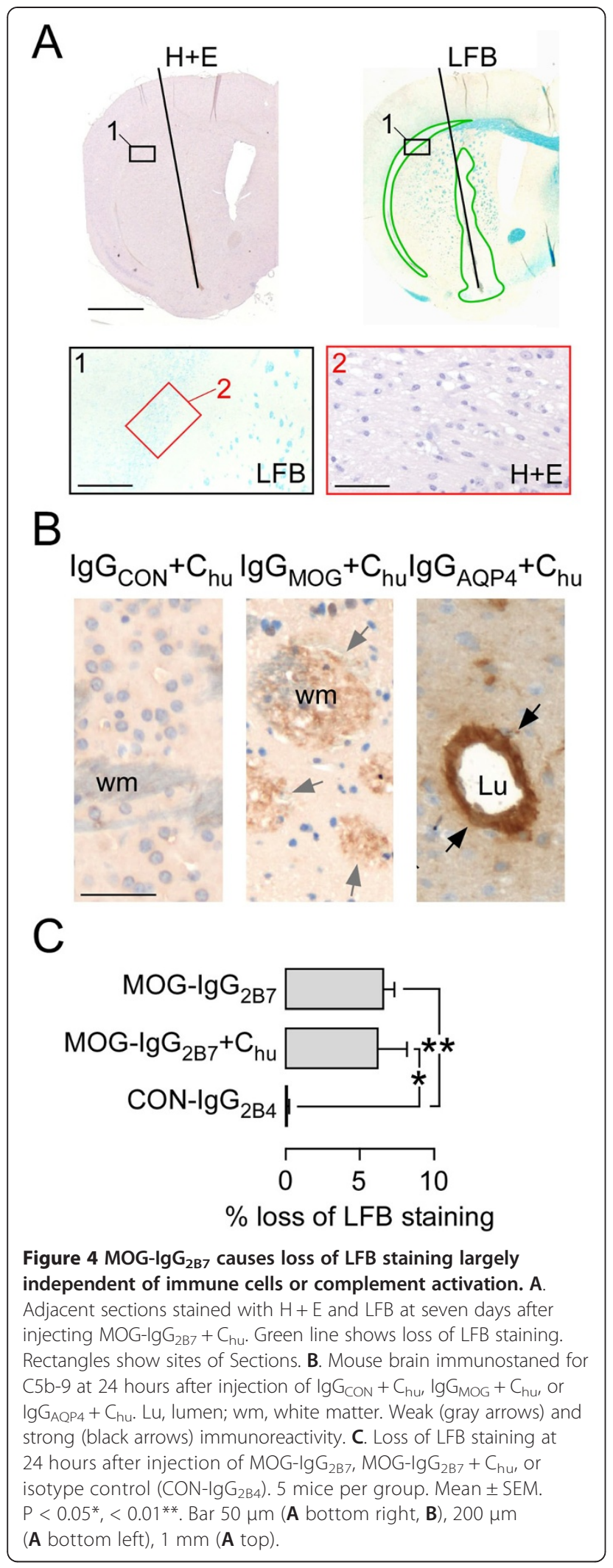

characteristic motor dysfunction including tremor and seizures [28], mice that lack Caspr have severe motor paresis [22] whereas mice lacking cerebellar ankG develop progressive ataxia [21]. Therefore, the altered MBP expression and reduced Caspr and AnkG expression produced by MOG-IgG are predicted to produce a neurological deficit if the NMO lesion is in an eloquent region of the CNS. Unlike AQP4-IgG, MOG-IgG did not produce axonal disintegration or neuronal death. Given the $96 \%$ homology between mouse and human MOG [14], our findings raise the possibility that MOG-IgG may also cause similar reversible lesions in the human CNS.

MOG-IgG has been reported in other non-NMO diseases including multiple sclerosis, acute disseminated encephalomyelitis and even some normal subjects [29]. Does MOG-IgG from these non-NMO subjects also cause the same reversible CNS changes, as described here for NMO MOG-IgG? This question is difficult to answer at present because of the variety of assays used to detect MOG-IgG. For example, the assay used here, which employs C-terminal truncated rather than fulllength MOG, did not detect MOG-IgG in adult multiple sclerosis patients and normal individuals [11], which suggests that different assays detect different subpopulations of MOG-IgG. It is important to first standardize the assays before determining which subpopulations of MOG-IgG can cause CNS damage and in which diseases.

The mechanism of MOG-IgG-induced myelin damage in vivo is unknown. Our data show that MOG-IgG mediated myelin damage is a direct effect of MOG-IgG and that complement activation is not necessary. MOGIgG binding may cause MOG conformational changes or internalization that disrupts the myelin structure and secondarily alters axonal protein expression. To explain the lack of complement involvement, we hypothesize that, after MOG-IgG binding, MOG might not aggregate (because of its low abundance) or MOG might become internalized (thus prohibiting $\mathrm{C} 1 \mathrm{q}$ activation). The full recovery within two weeks of the MOG-IgG-induced LFB, MBP, ankG and Caspr changes suggests that MOG-IgG does not kill the oligodendrocytes, but causes a reversible damage.

Our findings raise the possibility that MOG-IgG contributes to pathology in some NMO patients. If MOGIgG is pathogenic, antibody depletion (plasmapheresis) or suppression with steroids should be effective, as indeed appears to be the case $[10,11,15,16]$. Conversely, some of the newly proposed therapies for AQP4-IgG $\mathrm{NMO}$, such as sivelestat for inhibiting neutrophils [17], or eculizumab for inhibiting complement [30], are less likely to be needed in MOG-IgG NMO. Examining lesions from MOG-IgG NMO patients may help elucidate the pathogenicity of MOG-IgG in the human CNS. 


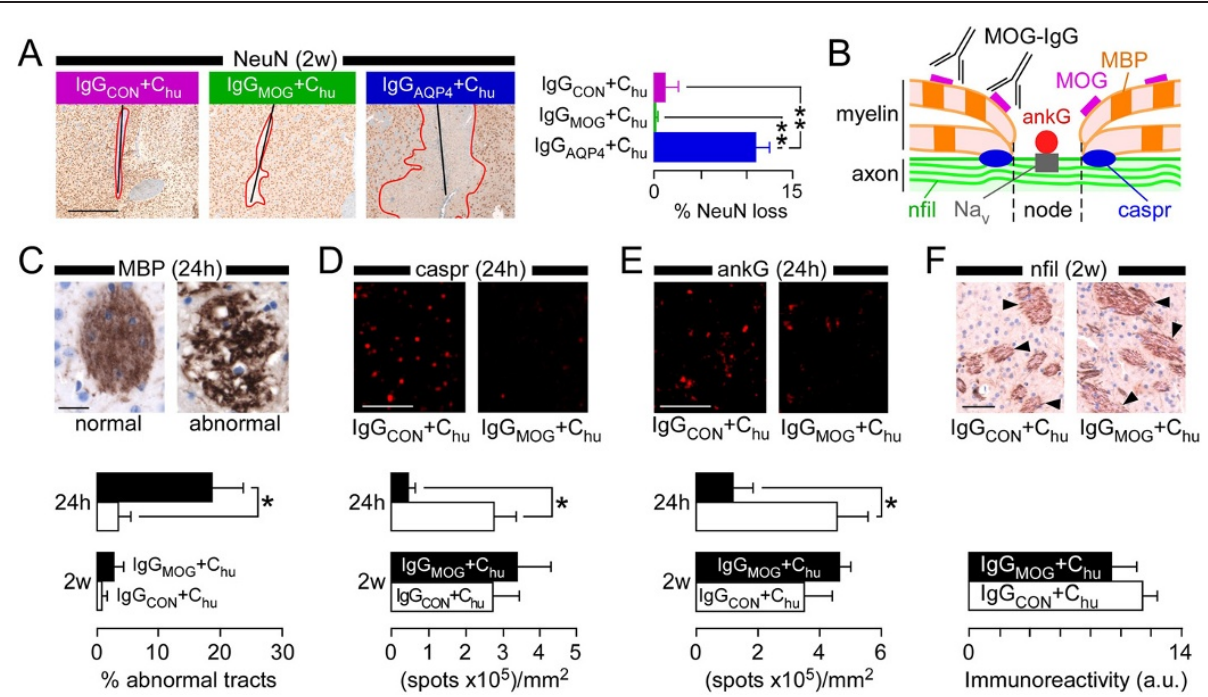

Figure 5 Effect of MOG-IgG on neurons. A. (Left) NeuN immunoreactivity at 2w. Area lacking neurons outlined red. (Right) \% NeuN loss (NeuN immunonegative area/ipsilatral hemispheric area). B. Node of Ranvier: ankG, ankyrin G; Caspr, contactin associated protein; MBP, myelin basic protein; MOG, myelin oligodendrocyte glycoprotein; $\mathrm{Na}_{v}$, voltage-gated $\mathrm{Na}^{+}$channel; Nfil, neurofilament. C. MBP immunoreactivity. (Top) Normal and abnormal white matter tracts. (Bottom) \% abnormal tracts in injected hemisphere. D. Caspr immunoreactivity within white matter tracts. (Top) Hemispheres injected with $\lg _{\mathrm{CON}}+\mathrm{C}_{\mathrm{hu}}$ and $\lg \mathrm{G}_{\mathrm{MOG}}+\mathrm{C}_{\text {hu. }}$ (Bottom) Data summary. E. AnkG immunoreactivity within white matter tracts. (Top) Hemispheres injected with $\lg G_{C O N}+C_{h u}$ and $\lg G_{M O G}+C_{\text {hu. }}$. (Bottom) Data summary. F. Nfil immunoreactivity. (Top) Hemispheres injected with $\lg G_{C O N}+C_{\text {hu }}$ and $\lg G_{M O G}+C_{\text {hu }}$. Arrowheads: white matter tracts. (Bottom) Data summary (a.u. arbitrary units). 5 mice per group. $P<0.05^{*},<0.01^{* *}$. Bar $0.5 \mathrm{~mm}$ (A), $20 \mu \mathrm{m}$ (C), $10 \mu \mathrm{m}$ (D, E), $50 \mu \mathrm{m}$ (F).

\section{Conclusions}

MOG-IgG obtained from neuromyelitis optica patients causes myelin changes and alters the expression of axonal proteins when injected in mouse brain. These effects are not associated with inflammatory cell infiltration, are largely independent of complement and recover within two weeks. AQP4-IgG obtained from neuromyelitis optica patients causes complement-mediated myelin loss, inflammatory cell infiltration, neuronal and astrocyte death with limited recovery at two weeks. These findings raise the possibility that MOG-IgG contributes to pathology in some neuromyelitis optica patients.

\section{Availability of supporting data}

No supporting data.

Table 1 Comparison of MOG-IgG with AQP4-IgG lesions in mouse brain

\begin{tabular}{|c|c|c|}
\hline Characteristic & MOG-IgG & AQP4-IgG \\
\hline Target cell & Oligodendrocyte (myelin) & Astrocyte (foot process) \\
\hline Lesion onset & Within hours of exposure to MOG-lgG & Within hours of exposure to AQP4-lgG \\
\hline Effect on astrocytes & No major effect (normal AQP4 and GFAP) & Astrocyte death (loss of AQP4 and GFAP) \\
\hline Effect on neurons & No major effect & Neuronal death (loss of NeuN, FJ-C staining [5]) \\
\hline Effect on oligodendrocytes & Change in myelin (loss of LFB) & Loss of myelin (loss of LFB) \\
\hline \multirow[t]{3}{*}{ Effect on axons } & Myelin (transient change in MBP) & Permanent loss of myelin \\
\hline & Intact axons (normal nfil) & Axonal degeneration ( $\beta$-APP expression [5]) \\
\hline & Node of Ranvier (transient change in casp and ankG) & \\
\hline Inflammatory cell infiltration & No & Yes \\
\hline \multirow[t]{2}{*}{ Complement activation } & Slight (in white matter tracts) & Marked (perivascular) \\
\hline & Not required for lesion to develop & Essential for lesion to develop \\
\hline Recovery & Yes, within 2 weeks & No, pan-necrosis followed by glial scarring \\
\hline
\end{tabular}

$\beta$-APP, beta amyloid precursor protein; FJ-C, fluorojade C; GFAP, glial fibrillary acidic protein; LFB, Luxol fast blue; MBP, myelin basic protein; NeuN, neuronal nuclear marker; nfil, neurofilament. 


\section{Abbreviations}

AnkG: Ankyrin G; AQP4: Aquaporin-4; AQP4-lgG: Aquaporin-4 lgG found in most neuromyelitis optica patients; C5b-9: Complement membrane attack complex; Caspr: Contactin associated protein; $C_{\text {hu }}$ : Human complement;

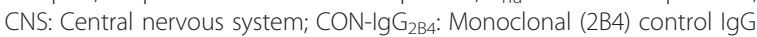
GFAP: Glial fibrillary acidic protein; $\mathrm{H}+\mathrm{E}$ : Hematoxylin and eosin; IgG $\mathrm{AOP}_{4}$ : lgG fraction of serum from neuromyelitis optica patients containing AQP4-lgG; IgG $G_{\text {CON: }}$ IgG fraction of serum from normal subjects; Ig $G_{M O G}$ : IgG fraction of

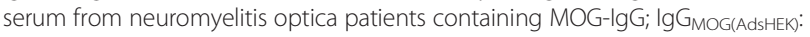
lgG $G_{\text {MOG }}$ adsorbed against untransfected HEK cells; IgGMOG(AdsMOG-HEK): IgGMOG adsorbed against MOG-HEK to deplete MOG-IgG; LFB: Luxol fast blue; MBP: Myelin basic protein; MOG: Myelin oligodendrocyte glycoprotein; MOG-lgG ${ }_{2 B 7}$ : Chimeric anti-mouse MOG recombinant lgG in which the constant mouse regions of the heavy and light chains were substituted with the human $\operatorname{lgG}_{1}$ constant regions, $\mathrm{C}_{H}$ and $\mathrm{C}_{\mathrm{K} . ;}$ N NeuN: Neuronal nuclei; Nfil: Neurofilament; NMO: Neuromyelitis optica.

\section{Competing interests}

The authors declare that they have no competing interests.

\section{Authors' contributions}

SS designed and carried out the animal experiments, analyzed the data, produced the figures, contributed key ideas and helped draft the manuscript. PW prepared the lgG patient samples and contributed key ideas. GPO produced the recombinant MOG-lgG antibody. JLB produced the recombinant AQP4-IgG antibody and contributed key ideas. AV contributed key ideas and helped to draft the manuscript. MCP participated in the design and coordination of the study and wrote manuscript. All authors read and approved the final manuscript.

\section{Acknowledgements}

Funded by a research grant from the Guthy Jackson Charitable Foundation to MCP. PW and AV are supported by the Oxford NIHR Biomedical Research Centre and the NHS Specialised Services for NMO. JLB is supported by the Guthy-Jackson Charitable Foundation and the NIH (EY022936). GPO is supported by the $\mathrm{NIH}$ (NS072141).

\section{Author details}

${ }^{1}$ Academic Neurosurgery Unit, St. George's, University of London, London, UK. ${ }^{2}$ Nuffield Department of Clinical Neurosciences, University of Oxford, Oxford, UK. ${ }^{3}$ Department of Neurology, University of Colorado Denver, Aurora, Colorado, USA. ${ }^{4}$ Department of Ophthalmology, University of Colorado Denver, Aurora, Colorado, USA.

Received: 9 March 2014 Accepted: 9 March 2014

Published: 31 March 2014

\section{References}

1. Waters PJ, McKeon A, Leite MI, Rajasekharan S, Lennon VA, Villalobos A, Palace J, Mandrekar JN, Vincent A, Bar-Or A, Pittock SJ: Serologic diagnosis of NMO: a multicenter comparison of aquaporin-4-lgG assays. Neurology 2012, 78(9):665-671. discussion 669. doi:10.1212/WNL.0b013e318248dec1.

2. Lennon VA, Kryzer TJ, Pittock SJ, Verkman AS, Hinson SR: IgG marker of optic-spinal multiple sclerosis binds to the aquaporin-4 water channel. J Exp Med 2005, 202(4):473-477. doi:10.1084/jem.20050304.

3. Papadopoulos MC, Verkman AS: Aquaporin water channels in the nervous system. Nat Rev Neurosci 2013, 14(4):265-277. doi:10.1038/nrn3468.

4. Hinson SR, Pittock SJ, Lucchinetti CF, Roemer SF, Fryer JP, Kryzer TJ, Lennon VA: Pathogenic potential of IgG binding to water channel extracellular domain in neuromyelitis optica. Neurology 2007, 69(24):2221-2231. doi:10.1212/01. WNL.0000289761.64862.ce

5. Saadoun S, Waters P, Bell BA, Vincent A, Verkman AS, Papadopoulos MC: Intra-cerebral injection of neuromyelitis optica immunoglobulin $\mathrm{G}$ and human complement produces neuromyelitis optica lesions in mice. Brain 2010, 133(Pt 2):349-361.

6. Papadopoulos MC, Verkman AS: Aquaporin 4 and neuromyelitis optica. Lancet Neurol 2012, 11(6):535-544. doi:10.1016/S1474-4422(12)70133-3.

7. Matiello M, Lennon VA, Jacob A, Pittock SJ, Lucchinetti CF, Wingerchuk DM, Weinshenker BG: NMO-IgG predicts the outcome of recurrent optic neuritis. Neurology 2008, 70(23):2197-2200.
8. Jarius S, Ruprecht K, Wildemann B, Kuempfel T, Ringelstein M, Geis C, Kleiter I, Kleinschnitz C, Berthele A, Brettschneider J, Hellwig K, Hemmer B, Linker RA, Lauda F, Mayer CA, Tumani H, Melms A, Trebst C, Stangel M, Marziniak M, Hoffmann F, Schippling S, Faiss JH, Neuhaus O, Ettrich B, Zentner C, Guthke K, Hofstadt-van Oy U, Reuss R, Pellkofer H, et al: Contrasting disease patterns in seropositive and seronegative neuromyelitis optica: a multicentre study of 175 patients. J Neuroinflammation 2012, 9(1):14. doi:10.1186/1742-2094-9-14.

9. Akman-Demir G, Tuzun E, Waters P, Icoz S, Kurtuncu M, Jarius S, Yapici Z, Mutlu M, Yesilot N, Vincent A, Eraksoy M: Prognostic implications of aquaporin-4 antibody status in neuromyelitis optica patients. $J$ Neurol 2011, 258(3):464-470. doi:10.1007/s00415-010-5780-4.

10. Kitley J, Leite MI, Kuker W, Quaghebeur G, George J, Waters P, Woodhall M, Vincent A, Palace J: Longitudinally extensive transverse myelitis with and without aquaporin 4 antibodies. JAMA Neurol 2013. EPub ahead of print. doi:10.1001/jamaneurol.2013.3890

11. Kitley J, Woodhall M, Waters P, Leite Ml, Devenney E, Craig J, Palace J, Vincent A: Myelin-oligodendrocyte glycoprotein antibodies in adults with a neuromyelitis optica phenotype. Neurology 2012, 79(12):1273-1277. doi:10.1212/WNL.0b013e31826aac4e.

12. Mader S, Gredler V, Schanda K, Rostasy K, Dujmovic I, Pfaller K, Lutterotti A, Jarius S, Di Pauli F, Kuenz B, Ehling R, Hegen H, Deisenhammer F, Aboul-Enein F, Storch MK, Koson P, Drulovic J, Kristoferitsch W, Berger T, Reindl M: Complement activating antibodies to myelin oligodendrocyte glycoprotein in neuromyelitis optica and related disorders. J Neuroinflammation 2011, 8:184. doi:10.1186/1742-2094-8-184.

13. Rostasy K, Mader S, Hennes EM, Schanda K, Gredler V, Guenther A, Blaschek A, Korenke C, Pritsch M, Pohl D, Maier O, Kuchukhidze G, Brunner-Krainz M, Berger T, Reindl M: Persisting myelin oligodendrocyte glycoprotein antibodies in aquaporin-4 antibody negative pediatric neuromyelitis optica. Mult Scler 2013, 19(8):1052-1059. doi:10.1177/1352458512470310.

14. Vourc'h P, Andres C: Oligodendrocyte myelin glycoprotein (OMgp): evolution, structure and function. Brain Res Brain Res Rev 2004, 45(2):115-124. doi:10.1016/j.brainresrev.2004.01.003.

15. Kitley J, Waters P, Woodhall M, Leite MI, Murchison A, George J, Kuker W, Chandratre S, Vincent A, Palace J: Neuromyelitis optica spectrum disorders with aquaporin-4 and myelin-oligodendrocyte glycoprotein antibodies: a comparative study. JAMA Neurol 2014. doi:10.1001/jamaneurol.2013.5857.

16. Sato DK, Callegaro D, Lana-Peixoto MA, Waters PJ, de Haidar Jorge FM, Takahashi T, Nakashima I, Apostolos-Pereira SL, Talim N, Simm RF, Martins Lino AM, Misu T, Leite MI, Aoki M, Fujihara K: Distinction between MOG antibody-positive and AQP4 antibody-positive NMO spectrum disorders. Neurology 2014. doi:10.1212/WNL.0000000000000101.

17. Saadoun S, Waters P, MacDonald C, Bell BA, Vincent A, Verkman AS, Papadopoulos MC: Neutrophil protease inhibition reduces NMO-lgG induced damage in mouse brain. Ann Neurol 2012, 71(3):323-333. doi:10.1002/ana.22686.

18. Saadoun S, Waters $P$, Macdonald C, Bridges LR, Bell BA, Vincent A, Verkman AS, Papadopoulos MC: T cell deficiency does not reduce lesions in mice produced by intracerebral injection of NMO-lgG and complement. J Neuroimmunol 2011, 235(1-2):27-32. doi:10.1016/j.jneuroim.2011.03.007.

19. Owens GP, Bennett JL, Lassmann H, O'Connor KC, Ritchie AM, Shearer A, Lam C, Yu X, Birlea M, DuPree C, Williamson RA, Hafler DA, Burgoon MP, Gilden D: Antibodies produced by clonally expanded plasma cells in multiple sclerosis cerebrospinal fluid. Ann Neurol 2009, 65(6):639-649. doi:10.1002/ana.21641.

20. Bennett IL, Lam C, Kalluri SR, Saikali P, Bautista K, Dupree C, Glogowska M, Case D, Antel JP, Owens GP, Gilden D, Nessler S, Stadelmann C, Hemmer B: Intrathecal pathogenic anti-aquaporin-4 antibodies in early neuromyelitis optica. Ann Neurol 2009, 66(5):617-629. doi: 10.1002/ana.21802.

21. Zhou D, Lambert S, Malen PL, Carpenter S, Boland LM, Bennett V: AnkyrinG is required for clustering of voltage-gated $\mathrm{Na}$ channels at axon initial segments and for normal action potential firing. J Cell Biol 1998, 143(5):1295-1304.

22. Bhat MA, Rios JC, Lu Y, Garcia-Fresco GP, Ching W, St Martin M, Li J, Einheber S, Chesler M, Rosenbluth J, Salzer JL, Bellen HJ: Axon-glia interactions and the domain organization of myelinated axons requires neurexin IV/Caspr/Paranodin. Neuron 2001, 30(2):369-383.

23. Mayer MC, Breithaupt C, Reindl M, Schanda K, Rostasy K, Berger T, Dale RC, Brilot F, Olsson T, Jenne D, Probstel AK, Dornmair K, Wekerle H, Hohlfeld R, Banwell B, Bar-Or A, Meinl E: Distinction and temporal stability of 
conformational epitopes on myelin oligodendrocyte glycoprotein recognized by patients with different inflammatory central nervous system diseases. J Immunol 2013, 191(7):3594-3604. doi:10.4049/jimmunol.1301296.

24. Marta CB, Oliver AR, Sweet RA, Pfeiffer SE, Ruddle NH: Pathogenic myelin oligodendrocyte glycoprotein antibodies recognize glycosylated epitopes and perturb oligodendrocyte physiology. Proc Natl Acad Sci U S A 2005, 102(39):13992-13997. doi:10.1073/pnas.0504979102.

25. Marta CB, Taylor CM, Coetzee T, Kim T, Winkler S, Bansal R, Pfeiffer SE: Antibody cross-linking of myelin oligodendrocyte glycoprotein leads to its rapid repartitioning into detergent-insoluble fractions, and altered protein phosphorylation and cell morphology. J Neurosci 2003, 23(13):5461-5471.

26. Lee DH, Linker RA: The role of myelin oligodendrocyte glycoprotein in autoimmune demyelination: a target for multiple sclerosis therapy? Expert Opin Ther Targets 2012, 16(5):451-462. doi: 10.1517/14728222.2012.677438.

27. Zhou D, Srivastava R, Nessler S, Grummel V, Sommer N, Bruck W, Hartung HP, Stadelmann C, Hemmer B: Identification of a pathogenic antibody response to native myelin oligodendrocyte glycoprotein in multiple sclerosis. Proc Natl Acad Sci U S A 2006, 103(50):19057-19062. doi:10.1073/pnas.0607242103.

28. Chernoff GF: Shiverer: an autosomal recessive mutant mouse with myelin deficiency. J Hered 1981, 72(2):128.

29. Reindl M, Di Pauli F, Rostasy K, Berger T: The spectrum of MOG autoantibody-associated demyelinating diseases. Nat Rev Neurol 2013, 9(8):455-461. doi: 10.1038/nrneurol.2013.118.

30. Pittock SJ, Lennon VA, McKeon A, Mandrekar J, Weinshenker BG, Lucchinetti CF, OToole O, Wingerchuk DM: Eculizumab in AQP4-IgG-positive relapsing neuromyelitis optica spectrum disorders: an open-label pilot study. Lancet Neurol 2013, 12(6):554-562. doi:10.1016/S1474-4422(13)70076-0.

doi:10.1186/2051-5960-2-35

Cite this article as: Saadoun et al:: Neuromyelitis optica MOG-IgG causes reversible lesions in mouse brain. Acta Neuropathologica Communications 2014 2:35.

\section{Submit your next manuscript to BioMed Central and take full advantage of:}

- Convenient online submission

- Thorough peer review

- No space constraints or color figure charges

- Immediate publication on acceptance

- Inclusion in PubMed, CAS, Scopus and Google Scholar

- Research which is freely available for redistribution 